\title{
A Systems Thinking Approach to Exploring the Influence of the Media on How Publics Engage With and Develop Dialogues Relating to Electric Vehicles
}

\section{OPEN ACCESS}

Edited by:

Anabela Carvalho,

University of Minho, Portugal

Reviewed by:

Pieter Maeseele,

University of Antwerp, Belgium

Irene Lorenzoni,

University of East Anglia,

United Kingdom

${ }^{*}$ Correspondence:

Shukru Esmene

s.esmene@exeter.ac.uk

Specialty section:

This article was submitted to Science and Environmental

Communication,

a section of the journal

Frontiers in Communication

Received: 12 November 2019

Accepted: 07 July 2020

Published: 14 August 2020

Citation:

Esmene S, Taylor TJ and Leyshon M (2020) A Systems Thinking Approach to Exploring the Influence of the Media on How Publics Engage With and Develop Dialogues Relating to Electric Vehicles. Front. Commun. 5:59. doi: 10.3389/fcomm.2020.00059

\author{
Shukru Esmene ${ }^{1 *}$, Timothy J. Taylor ${ }^{2}$ and Michael Leyshon ${ }^{1}$ \\ ${ }^{1}$ Centre for Geography and Environmental Science, College of Life and Environmental Sciences, University of Exeter, Penryn, \\ United Kingdom, ${ }^{2}$ European Centre for Environment and Human Health, University of Exeter Medical School, Truro, \\ United Kingdom
}

Electric vehicles (EVs) are the most popular alternative to petrol and diesel vehicles and are becoming a central part of climate change mitigation strategies. This paper draws attention to how publics engage with communication strategies relating to EVs. By focusing on the interlinked relationships between an individual's location, socio-demographic characteristics and their experiences with media sources, the paper demonstrates how EV-related knowledges are publicly engaged with. By using systems thinking as a critical analytical lens, we examine how these individuals use knowledges and/or refer to hegemonic framings of alternative technologies to discuss EVs. These constructs focus predominantly on consumerist framings of EVs and how they compare to petrol and diesel vehicles as a commodity. In this context, the paper provides an understanding of how to improve public engagement with EV-related communications by using a systems thinking approach. In doing so, the paper further offers a critical perspective on the relevance of EVs to publics beyond being a consumer product. These considerations can provide researchers with valuable insights into effective and more engaging communication strategies for particular contexts.

Keywords: science communication, public understanding of science, electric vehicles, climate change mitigation, systems thinking

\section{INTRODUCTION}

Research on the perceived threats of climate and environmental change to society has drawn attention to the need for improved mechanisms of science communication (Barr, 2011; Moser, 2016; Guenther et al., 2018). Translating scientific and technical knowledges into accessible and engaging sources for publics is, despite voluminous communications research (Moser, 2016; Burke et al., 2018), proving an ongoing concern. Contemporary studies highlight that public interactions with scientific knowledges and the generation of public-wide discourses around these knowledges is not a simple linear process from knowledge deficit to one of knowledge acquisition as publics actively construct knowledges (Chilvers, 2013). The reasons why publics develop an interest in scientific discourse and become active in these discourses is a messy and complicated process that reflects both the unevenness of their lived realities and how they interact with, and shape 
information (Sheppard, 2015). In this paper we start from a position of acknowledging the messiness of how publics engage with and shape knowledge, and recognize that scientific dialogues rarely occur directly between publics and researchers. It is axiomatic that in an ever increasingly socially connected world many actors play roles in translating, reconstructing and mediating science (Moser, 2014). However, their influence on the translation and engagement in new scientific technologies requires further critical analysis. To illustrate the importance of non-academic actors in science communication we focus on the "media" as a complex amalgam of translational sources (Tiessen et al., 2008; Burke et al., 2018). The media actively construct, deconstruct and reconstruct knowledges based on specific agendas and ideological stances (Carvalho, 2007). This study investigates a certain component of public interactions with the media. We explore the media's influence on public discourses at the inception of a technology, i.e., EVs, becoming more widely relevant to publics, and media coverage acting as initial sources of knowledge. We pay attention to media sources relating to EVs that have been encountered by publics during their day-to-day lives.

Engaging with publics with varied contextual characteristics, such as rural-urban living, socio-demographics, existing behaviors and preconceptions around a specific topic, and general engagement with scientific knowledges is essential for developing our understanding in this area (Wolf and Moser, 2011). These characteristics are interlinked, often place-based, and tend to provide the reasoning behind why individuals may engage with particular knowledges (Schweizer et al., 2013). Understanding how these characteristics influence engagement can help in engaging publics beyond hegemonic framings of a technology. This particularly relates to the development of public dialogues around the contextualized applications of scientific and technological knowledges (Klein and Kleinmann, 2002; Ryghaug et al., 2011). Further, we acknowledge that these characteristics and the ways in which they interplay can begin to define specific responses to EV-related communications. For example, more critical dialogues can occur when individuals are given the opportunity to move beyond hegemonic, normative, consumer-based framings of the EV, which are commonplace in neo-liberal societies (Irwin and Michael, 2003; Rudman, 2006). Thus, understanding these characteristics, whilst acknowledging how they are shaped by societal discourses (often reflected and influenced by the media), will result in the development of science communication strategies that encourage active and critical engagement with publics. In turn creating the ability to reach individuals at a higher resolution and generate better embedded scientific discourses amongst these publics. A higher resolution in this sense refers to a strategy's ability to respond to individualized, place-based variances within a public (Schweizer et al., 2013). To address the complexity inherent in how publics interact with communications regarding climate change related alternative technologies (i.e., EVs), this study engages with both the heterogeneity of individuals and groups, and how this influences their interactions with media sources about new topics, e.g., EVs.
This paper draws attention to how interacting with mediated communications on EVs at a personal level can have manifold responses, including engagement, disengagement and remaining unaffected. We also recognize that even though individuals in a public may share certain contextual characteristics, such as socio-demographic status, the influence of these characteristics on their interactions with sources of communication can differ significantly and each characteristic cannot be individually linked to a discrete influence (Martens et al., 2009). This is where systems thinking can be used to establish how publics interact with EV-related media communications and understand how publics construct dialogues based on the communications they interact with. Systems thinking, which has previously been deployed in debates on public health (Leischow et al., 2008; Byass, 2011), maps how characteristics and specific actors are arranged in particular contexts to enable communication (Best and Holmes, 2010; Byass, 2011). Essentially, systems thinking considers the contexts communication occurs in and the characteristics of the individuals that interact with the communications (Kalim et al., 2006). This form of holistic analysis aids the exploration of how publics engage with, and form dialogues on, the information and critical perspectives outlined by a communication (Jackson, 2000). Consequently, a system is created around how publics engage with communication sources and framings of topics that can capture attention and/or are most relevant. This system is based on certain individual and collective characteristics and provides a framework for understanding how interactions, and consequent dialogues, are influenced by the complex interconnections between these characteristics (Hernández et al., 2017). These interactions and how public dialogues develop can provide indicators of how specific publics can be best engaged by future communications that provide deeper insights from a wider range of perspectives. In some contexts, these perspectives can be more relevant to publics compared to homogenous framings of knowledges. Systems thinking may seem to be a functional response to an issue impacted by complex and societally embedded contextualities, such as political dominance and governance structures. However, we deploy the approach, to explore an existing system in relation to publics and their encounters with EV-related media communications in a particular case. We do not set out to generalize our findings to other cases, but we present an approach that can be used to explore the contextual complexities in other cases around the issue we study. Overall, this study addresses two questions via the application of systems thinking as an analytical tool. The questions are as follows:

(i) How do contextualities shape interactions with communications and consequent public dialogues relating to EVs? These include societal hegemonies, which influence prevalent discourses relating to issues that publics are exposed to, and existing preconceptions around a specific topic such as alternative technologies.

(ii) How do public encounters with media communications shape their engagement and initial dialogues around EVs? 
Both questions are interlinked. They set out to understand how publics, media communications accessible to publics and contextual characteristics merge to influence public perspectives and dialogues. This paper adds to the literature on science communication by providing a holistic understanding of how EV-related knowledges enter public domains and influence public dialogues (Moser, 2016; Burke et al., 2018). We draw attention to how societal structures, often shaped by neo-liberal hegemonies, and cultural traits influence the communications publics access and engage with.

In the following sections of this paper, we discuss the complexity and context specific variance of how publics interact with scientific and technological knowledges related to climate change. We use advanced thinking on climate change communication as an entry point to debate EVs in this context. EVs are often presented as a component of mitigating climate change (Nanaki and Koroneos, 2016). However, our intention is not to draw a direct comparison with climate change's scale and urgency, but rather to explore the extent to which learning from climate change communication strategies can add a new dimension to inspiring public dialogues about EVs. We then introduce our novel approach; the application of systems thinking as an analytical lens. This is presented in the context of societal characteristics and structures that shape publics, i.e., politics and societal hegemonies. We then move on to outline how communications placed into public domains by the media have previously impacted public perspectives regarding climate change related technological knowledges.

\section{PUBLICS AND COMMUNICATION}

We acknowledge that communicating scientific and technological knowledges reflexively to publics is a welldeveloped field (Chilvers, 2013). In this study, we explore this process through systems thinking, without oversimplifying contextualities, to ascertain the state of communication in a specific context. We observe EVs as a technological advancement associated with climate change and therefore draw from the literature around communicating climate change to frame our study. Climate change communication literature has sought to understand how to translate a largely intangible, often "remote" phenomenon into a personal, relatable and prescient issue for individuals (Sheppard, 2015).

In relation to the engagement of publics in the communication and shaping of EV knowledges, we present a key mechanism from climate change communication literature to highlight the need for more contextualized research around EVrelated communications. Research in climate change communication illustrates that temporalities of science communication occur depending on the context where actors interact with specific knowledges (Sheppard, 2015). Thus, knowledges can be perceived and used by the same actor in contradictory ways depending on their circumstances
(Latour and Weibel, 2005). This ongoing reframing of the same knowledges contextualizes dialogue. To emphasize this point we set out our argument below that actors in a variety of contexts can create different dialogues around the same knowledge.

Hence, we focus on two main sites of communication and dialogue; (i) the public (or, as discussed below, diverse publics) and (ii) the media communications publics can access. Further, the political structures and societal hegemonies underpinning actors involved in communicating, receiving, interpreting and shaping EV-related knowledges need to be acknowledged. Therefore, the following section presents how publics interact with science communication. Significantly it examines the influence of context (geographical, social, cultural, socio-demographic, and their interlinked impacts) on communicating to publics and how such communications can shape public perspectives. Following on from this, we discuss the political structures and hegemonies influencing EV-related communication, and introduce systems thinking to demonstrate how these structures outline the conditions within which communication and public constructs can occur. Finally, we present the media as a key actor in shaping knowledges publics access and in turn construct their own dialogues around.

\section{Public Interactions With Climate Change Knowledges}

Science communication literature habitually categorizes the "public" as a heterogeneous group (Trench and Miller, 2012), which can receive and be active in climate change communication in a multitude of ways. This is dependent upon the precise context and constitution of a public, i.e., their sociodemographic, geographical, social, and cultural characteristics (Spence et al., 2011; Welsh and Wynne, 2013). Heterogeneous publics are often conceptualized under an "umbrella" term of "diverse publics" (Barr, 2011). They may be "emergent" entities (Mahony, 2014), forming within particular social, cultural and geographical settings, and/or in response to specific issues. However, they are ultimately defined through shared characteristics, including but not limited to socio-economic status, age, gender, political stance, environmental values and education (Miller et al., 2007; Ryghaug et al., 2011). These characteristics have been studied extensively in relation to general climate change (Boykoff, 2014; O’Neill, 2019). However, their influence on communications relating to alternative technologies associated with climate change remains understudied. We address this gap in this paper.

"New" publics may be "created" in relation to new phenomena, issues, and sets of knowledges, products and technologies (Barr, 2011). For example, early EV adopters became a new and distinct "public" at their inception, with a shared environmental motivation (and associated technicity) driving their EV engagement (Plotz et al., 2014). Therefore, their involvement in EV communication, how they receive such communications and how their perspectives develop overtime, cannot be assumed to be transferable to other publics (Barr, 
2011). Importantly, these highly sophisticated individualized interactions with knowledge can only emerge if publics are able to relate to a topic, in this case an alternative technology, beyond how they are naturalized by societal structures. These structures are linked to political framings and societal hegemonies, often constructed through the neoliberal commodification of objects and subjects (Lave, 2012).

If such structures are penetrated, the inherent complexities formed by heterogenous publics renders communication a reflexive process as opposed to being reliant on prescriptive models of best practice (Chilvers, 2013). As climate change communication researchers have already recognized: "no one theory will explain the variation in human experience of climate change" (Wolf and Moser, 2011, p. 547). Even though we are concerned with a much smaller component of climate change, this study adopts an innovative case study approach to draw attention to how publics construct their own dialogues about EVs based on media communications. This is achieved through documenting individualized experiences within multiple publics. The next section outlines how political structures and the ways by which society is organized (societal hegemonies) impact communication. We also highlight how systems thinking can be applied to better understand the influence of these structures on communication.

\section{Political Structures, Societal Hegemonies, and the Application of Systems Thinking}

The political landscape plays an important role in shaping public perceptions of, and interactions with, technological and scientific knowledges. In this sense, the most simplistic consideration is the increased levels of public trust placed in communications that align with prevalent political ideologies (Irwin and Michael, 2003; Nowotny, 2014). Additionally, hegemonic political structures that impact power relations in a society play a role in what types of communications are readily accessible and placed in public domains (Jerit et al., 2006). At points in this paper we speak exclusively about these influential factors due to their clear impact on how publics interact with certain scientific and technological knowledges. However, it should be clarified that, like public characteristics (e.g., socio-demographics and rural vs. urban living), these factors are interconnected and interplay with the trust of publics (Miller et al., 2007; Nowotny, 2014). Increased trust levels, through political alignment, influence how knowledges relating to alternative technologies enter and are further developed by publics (Wynne, 1992; Nowotny, 2014).

Alternative technologies, such as EVs, become a subject of the hegemonies that emerge from political structures and how these structures frame the technologies influence how they become public (Latour and Weibel, 2005). The political structures that influence hegemonic dialogues revolve around how society is governed and configured at an organizational level. These are defined by politics and power, and the governance of priorities (e.g., the economy, education and population health) that are presented as indicators for a successfully functioning society (Verger et al., 2014). Barr et al. (2011, p. 713) make this point directly in relation to transportation by stating, "Indeed, it is unlikely that current political and economic conditions in most western democracies favor anything but the current Neo-liberal approach toward social and environmental policy making."

A neo-liberal society that commodifies technology and creates consumerist competition between products often struggles to move beyond knowledges that resonate with consumer needs and desires (Lave, 2012). For instance, EVs remain as the main alternative to petrol and diesel vehicles. Therefore, civic spheres tend to interact with EV communications through existing dominant dialogues relating to petrol and diesel vehicles (Egbue and Long, 2012; de Rubens et al., 2018). de Rubens et al. (2018) demonstrate the impact of this by outlining how misinformation and negative constructs regarding EVs can occur when they are commodified. Essentially, if their performance, price tag, and/or economic viability falls short from a supplier and/or consumer perspective their qualities relating to the environmental issues they aim to mitigate can become redundant in civic spheres (Lebeau et al., 2013).

Systems thinking can be used to explore the connections individuals, groups, and organizations have with structures (usually political) that define hegemonies. Additionally, it can be used to investigate other mechanisms that allow publics to engage in meaningful dialogue relating to certain subjects like EVs (Toscano, 2006). Through this approach, we can document the early knowledges that publics encounter around a new topic and their sources. In so doing, we can understand how knowledges are framed in the sources publics are likely to come across and the ways in which this has influenced initial dialogues around a new topic. Therefore, using systems thinking enables this study to draw attention to the latent opportunities in engaging publics with EV-related knowledges beyond their prevalent, and often homogenous, framings.

\section{The Media and Communication to Publics}

The media, in this case defined as the primary news sources that publics encounter and have access to on a daily basis (Boykoff and Boykoff, 2007), are actors that publics draw upon. Publics can interact with the media through reading hard copies of newspapers, watching the television or accessing online news content (Boykoff and Boykoff, 2007; Tiessen et al., 2008; van Witsen and Takahashi, 2018). Media coverage of alternative technologies, such as EVs, offers a potentially valuable indicator of how and which knowledges are available in the public domain (Hajer and Stengers, 2012; Schmidt et al., 2013; Boykoff, 2014). The dominant framings of knowledges can be explored too. Knowledges communicated by the media are often defined by the political agenda of a media organization. Hence, their communications often construct and reconstruct knowledges to support the political rhetoric of particular media organizations. Boykoff and Boykoff (2007) referred to this influence on communication as a primary journalistic norm. Further, Grundmann and Scott (2012) and Boykoff (2014) have illustrated that newspapers whose owners are skeptical of anthropogenic climate change over-inflate the importance of a study denying its effects, generalizing the findings of the study from one specific context to all contexts. Such communications overlook the general academic consensus on climate change and 
veil critical perspectives that do not align with certain agendas (Painter and Gavin, 2015).

The media's role in framing scientific knowledge, when they have strong political and ideological standpoints, can render them as influential actors in shaping public dialogues around science and technology (Carvalho, 2007; Boykoff, 2014; Feldman et al., 2015). Moreover, individuals tend to interact with media outputs (specific newspapers, television/radio shows etc.) that they have traditionally been exposed to, for example via parents or peers (Chan and Goldthorpe, 2007). Alternatively, where traditional influences are weaker, individuals will likely favor media organizations whose content aligns with their personal views, values and identities (Chan and Goldthorpe, 2007; Lott and Hasset, 2014). In this instance the print media available to publics becomes a major actor in shaping public dialogues. Media messaging, particularly on climate change related communication relevant to EVs, take on different forms. This again links closely to how different types of print media situate themselves within political structures and societal hegemonies to define their ideological stances, and appeal to the consumers they aim to target (Olausson, 2009; Painter and Ashe, 2012). Overall, these media-based norms, will effectively influence the initial messages publics interact with, and therefore the dialogues they form, around climate change related issues (Tiessen et al., 2008). At this point, we must recognize that media communications cannot be regarded as an exclusive or singularly observable influence on public dialogues. However, we can begin to document the knowledges that are available in the public domain by detailing the media framings publics can access and have interacted with.

EVs are often included in this domain of dialogues as a low-carbon alternative technology (Langheim et al., 2014). They are referred to as a component of climate change, which itself has been studied extensively in terms of media framing and public dialogue (Boykoff and Boykoff, 2007; Tiessen et al., 2008; Olausson, 2009; Boykoff, 2014; Langheim et al., 2014; O’Neill, 2019), but EVs themselves are yet to be researched in any detail with regards to media framing and public dialogue. In this study, we explore EV-related media communications available to publics through their own experiences. Our findings discuss the media sources this study's participants had encountered and their EV-related dialogues. Before this, we outline our methods in Section Methods.

\section{METHODS}

\section{The Case Study: Cornwall, UK}

This study was part of a wider PhD study exploring the communication of EV-related knowledges across a wide range of actors, i.e., beyond the focus of this paper. A series of focus groups, outlined in more detail below, were conducted directly after the UK Government had awarded various regions with funding to scope and develop EV-related infrastructure (UK Government, 2012). We focus on a site that had their application for funding rejected; Cornwall, UK.

Cornwall is the UK's most south-westerly region and offers a novel geographical setting in which to explore how
EV-related communications are engaged with by publics. Pertinent to the time of this study (January 2014), the UK Government's 2012 Plug and Places (PIP) grant of $£ 37$ million to fund new EV charge points did not extend to Cornwall. By January 2013, only 11 EVs had been purchased in the entire county. This study was conducted during this lowadoption period. Hence, the participants that took part in this study would have had limited opportunities to personally experience and/or familiarize themselves with EVs. Cornwall predominately comprises of rural settlements, as classified by the UK's Office for National Statistics (ONS), with populations of below 10,000 people (ONS, 2011). However, it does have 10 settlements classified as urban. St. Austell is the largest single settlement with a population of 27,400 people (ONS, 2011). Most existing studies on EVs focus on inhabitants in large urban centers (e.g., Brady and O'Mahony, 2011) but in this study we include rural and urban perspectives by conducting focus groups with residents in both rural and urban areas of Cornwall.

\section{Focus Group Structure and Locations Within Cornwall}

Systems thinking was used to inform the structure of the focus groups we conducted. As Krueger (2002) recommends, the focus groups we designed were formulated around open questioning. We were ultimately interested in (i) what publics knew about EVs; (ii) the media sources publics had encountered and interacted with in relation to EVs; (iii) how they related to any specific EV-related communications they came across in these media sources; and (iv) how publics discussed EVs based on their existing knowledges and what they encountered in media sources. Our systems thinking framework aimed to pick up how specific characteristics, e.g., socio-demographic characteristics, interlinked with media communications to inform dialogues around EVs.

In order to capture insights from both rural and urban residents, and to maximize the opportunity to engage with highincome and low-income residents, the focus group locations were identified using two national datasets:

(i) The Rural Urban Classification (ONS, 2011). This uses a "morphology" variable to identify areas within Cornwall described as "rural" (e.g., villages, hamlets, or isolated dwellings) or "urban" (settlements with a populations $>10,000$ people).

(ii) The Index of Deprivation (DCLG, 2010). This uses area-level income data to create income score deciles for settlements in the UK.

Each of these datasets comprise area-level (rather than individual) statistics, focusing on Lower Layer Super Output Areas (LSOAs). The two datasets mentioned above were integrated after creating the income decile variable within the software package Stata. Each LSOA had a corresponding morphology and income decile value. The combined dataset was imported into a Geographical Information System program 
(Quantum GIS v1.8), and the LSOAs with the following characteristics within Cornwall were highlighted:

- "Rural," income deprivation decile (IDD) 1-4.

- "Rural," IDD 7-10.

- "Urban," IDD 1-4.

- “Urban," IDD 7-10.

An income decile of 1-4 refers to less deprivation and 7-10 refers to higher levels of deprivation.

Two LSOAs per category were then identified and used to select eight focus group locations. This was done with the aim of achieving a relatively even geographical spread across the county, as illustrated in Table 1 and Figure 1.

\section{Focus Group Participant Sampling and Recruitment}

A purposive sampling approach was used as implemented by similar studies (Nicholson-Cole, 2005; Miller et al., 2007; McClanahan et al., 2009; Ryghaug et al., 2011). This ensured the recruitment of "information-rich" participants to each focus group (Patton, 1990). A purposive sampling matrix (Table 2) was created to capture a range of characteristics in the urban and rural focus group locations (as discussed above). The matrix includes age, gender, socio-economic status and education.

In addition to these characteristics, the study inclusion was informed by the need to be in possession of a valid UK driving license. Wynne (1992) suggests that personal experience and self-identity with the technology and/or product in question can influence public understanding. Since this study focuses on an alternative (the $\mathrm{EV}$ ) to the conventional mode of personal transport (petrol and diesel vehicles), familiarity with driving a petrol or diesel vehicle was deemed to be an important criterion.

Finally, individuals who were professionally involved in academia, the media and environmental and/or EV-related industries were excluded. This was to ensure that focus group discussions were not dominated by anyone with occupational links or a significantly advanced knowledge-base regarding the core focus of this study (Rawlins and Bowen, 2005).

Participants were recruited to each group on the basis of the sampling criteria set out in the purposive sampling matrix in Table 2. Overall, the groups in Truro, Roche North, Saltash, Penzance, and Mawnan Smith had eight participants

TABLE 1 | Focus group locations and characteristics.

\begin{tabular}{ll}
\hline Socio-economic status & Location \\
\hline Rural IDD 7-10 & Pendeen \\
Urban IDD 7-10 & Newquay \\
Rural IDD 7-10 & Roche North \\
Urban IDD 7-10 & Penzance \\
Rural IDD 1-4 & Mawnan Smith \\
Urban IDD 1-4 & Truro \\
Rural IDD 1-4 & Fowey \\
Urban IDD 1-4 & Saltash
\end{tabular}

each, and the Newquay and Pendeen focus groups had six participants. Finally, five participants were present during the Fowey focus group (the location of each focus group site within Cornwall can be seen in Figure 1). Further, in order to enhance opportunities for positive group dynamics, Hoggart et al. (2002) advocate ensuring a degree of homogeneity within groups in relation to characteristics that could create tensions. Since these focus groups were specifically interested in aspects of public understanding and public interactions with EV-related communications, a somewhat expensive technology, it was decided to keep the groups relatively homogenous in terms of income.

Once the sampling framework had been finalized, a recruitment screening questionnaire was devised to capture the intended purposive sample, and a third party was used to carry out the participant recruitment. The third-party organization approached residents with the relevant characteristics and invited them to take part in a focus group. EVs were not mentioned at the time of recruitment so as not to limit the group to individuals with pre-determined interests in EVs. Instead the groups were framed as a discussion around road transport in the local area.

\section{Focus Group Analysis}

The focus groups were between 2 and $3 \mathrm{~h}$ in duration and followed an initial discussion about road transport. The opening section was used as a platform to focus the discussion around the environmental impacts of transport systems. Interestingly, EV-related discussions did not develop organically in any of the focus groups. Hence, the participants were directly invited to give their opinions on EVs, and the focus group proceeded to develop discussions on what the participants knew about EVs, where they had heard about EVs, i.e., in media sources, and what their perspectives relating to EVs were in relation to their social contexts.

The focus group transcripts were subjected to inductive Qualitative Content Analysis (QCA) (Schreier, 2012). QCA is a well-established analytical method with a long history of use across disciplines such as communication, journalism, human geography and sociology (Elo and Kyngäs, 2007). Through a systematic process of coding and categorization, it aims to "attain a condensed and broad description of a phenomenon" (Elo and Kyngäs, 2007, p. 108). Hence, analysis can focus on manifest (clear) and latent (hidden) themes.

Essentially, an inductive QCA approach was adopted to let the data lead the findings. The coding approach was regularly discussed by two researchers, with one researcher acting as "critical friend," to ensure a reflexive approach to data interpretation and coding (Foulger, 2009). As noted by Schreier (2012), this helps to capture maximum detail within a given context and ensures that novel theoretical contributions that may be unique to the specific case under study are not overlooked (Patton, 1990).

These emergent findings then were used to draw on systems thinking, which created a holistic view of how this study's participants, i.e., publics, interacted with media sources to inform 


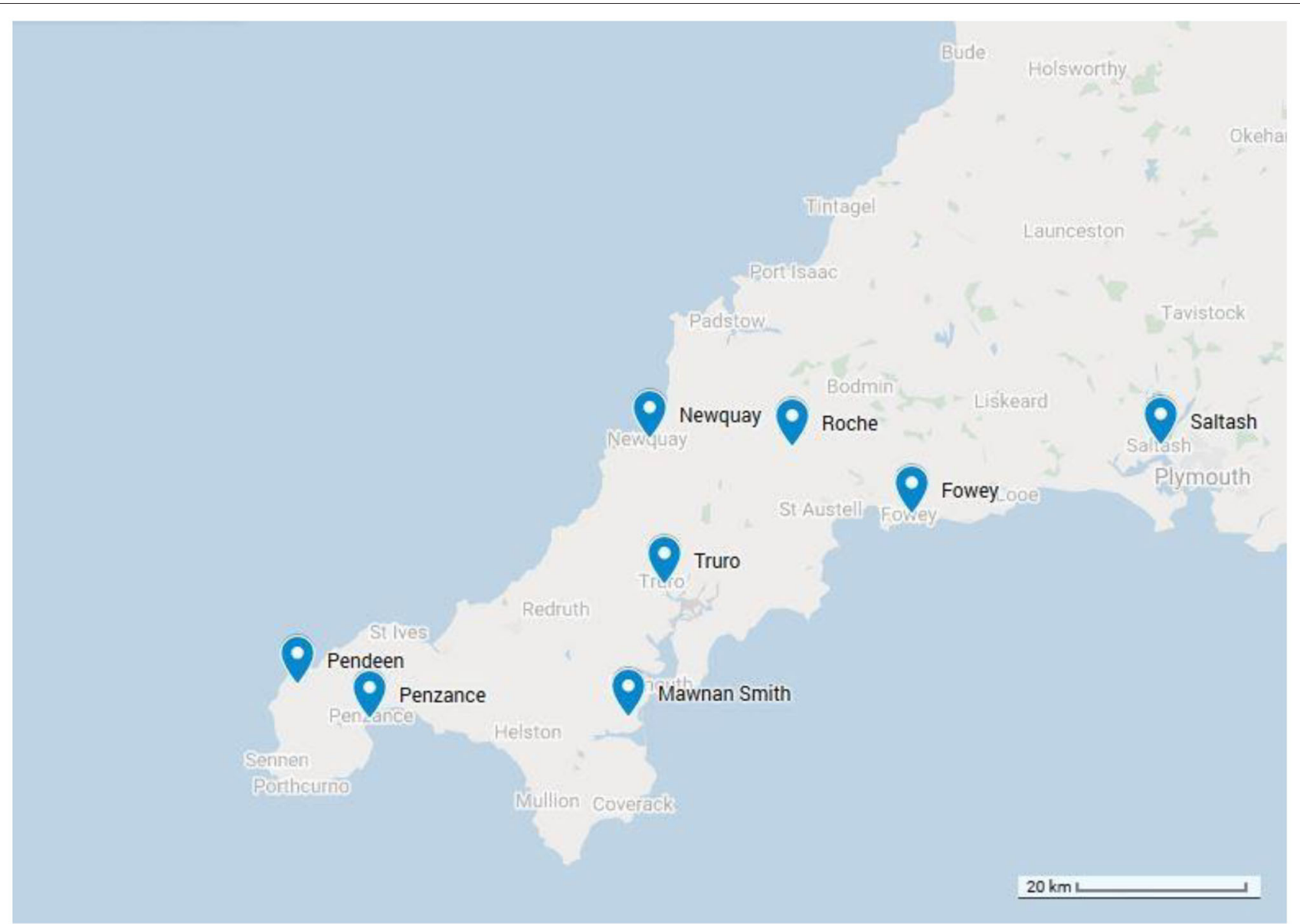

FIGURE 1 | Focus group locations within cornwall, UK. Map data $\odot 2020$ Google.

TABLE 2 | Purposive sampling matrix used to guide focus group recruitment.

\begin{tabular}{|c|c|c|c|c|c|}
\hline $\begin{array}{l}\text { Focus } \\
\text { group } \\
\text { no. }\end{array}$ & $\begin{array}{l}\text { Rural/ } \\
\text { urban }\end{array}$ & $\begin{array}{l}\text { *Household } \\
\text { income }\end{array}$ & $\begin{array}{l}\text { Education } \\
\text { Level }\end{array}$ & Age & Gender \\
\hline 1 & Rural 1 & Low-Medium & Secondary & $\begin{array}{l}\text { Representative of } \\
\text { the age } \\
\text { distribution in } \\
\text { Cornwall (Cornwall }\end{array}$ & $\begin{array}{l}50: 50 \\
\text { Male/ } \\
\text { Female } \\
\text { for all }\end{array}$ \\
\hline 3 & Rural 3 & Medium- High & Secondary & Council, 2011) & groups \\
\hline 4 & Rural 4 & Medium- High & Higher & Assuming 7 & \\
\hline 5 & Urban 1 & Low-Medium & Secondary & $\begin{array}{l}\text { people per group: } \\
\text { Age 18-30: } 2\end{array}$ & \\
\hline 6 & Urban 2 & Low-medium & Higher & Age 31-50: 1 & \\
\hline 7 & Urban 3 & Medium- High & Secondary & Age 51-64: 1 & \\
\hline 8 & Urban 4 & Medium- High & Higher & $\begin{array}{l}\text { Age } 65+: 2 \\
\text { "Extra": } 1 \text { (in case } \\
\text { of drop-out) }\end{array}$ & \\
\hline
\end{tabular}

and construct their own dialogues around EVs. In this case, the system we observed was created by publics, their context, their existing opinions and knowledges regarding EVs and the media communications they encountered relating to EVs.

\section{RESULTS AND DISCUSSION}

The findings presented in this section highlight the benefit of indepth qualitative approaches. The media sources recalled by the participants were said to be relatively brief, simply presenting EVs as a purchasable (consumer) alternative good to petrol and diesel vehicles. Additionally, the low adoption and lack of opportunities in Cornwall, UK to familiarize with EVs (at the time of data collection) meant participants had, unsurprisingly and understandably, not given much thought to them. However, due to the dialogically constructive nature of our methods we were able to respond to the context generate discussion.

\section{Participant Dialogues on Electric Vehicles}

The opening discussion in each group was framed around their perspectives regarding major environmental impacts from road transport. This generated relatively homogenous responses around traffic, noise and air pollution. Notably, no-one in any of the focus groups brought EVs into conversation until prompted to do so.

Since EVs were not volunteered as a topic of conversation by anyone at this point, they were deliberately introduced into discussion by the researcher. Significantly, participants in each 
focus group had only interacted with EV-related communications in the national print-media. From a systems thinking perspective, this limited the actors involved in communication and the knowledges that could circulate and be shaped publicly. The influences on dialogue that can be tracked by systems thinking are closely aligned with how knowledges are framed (Hernández et al., 2017). In this case, the framing of EVs as a consumer product was the main media messaging participants recalled and spoke about and dialogues struggled to move beyond this convention due to the lack of direct experience and familiarity with EVs amongst the participants.

Fundamentally, media communications recollected by the participants (contributing to their knowledge-base) focused on EVs as a consumer product. An individual's existing knowledge should not be equated to their opinions about a topic, but it does act as a platform for dialogue in circumstances where knowledges are new and developing (Wals et al., 2011). Further, the limited participant dialogues that took place could simplistically be attributed to personal inadequacies around knowledge, yet a systems thinking interpretation implies that this is reflective of the constrained knowledges that publics encounter during their daily lives. Each focus group raised concerns about the purchase costs of EVs. This was the most discussed subject in each group (apparent amongst both rural and urban groups), which is consistent with much of the existing social science literature framing EVs as a consumer-oriented purchasable product (Graham-Rowe et al., 2012; Axsen and Kurani, 2013; Carley et al., 2013; Bunce et al., 2014; Peters and Dutschke, 2014). This concern seemed to have acted as a significant barrier to engaging more deeply with EV-related communications and indeed EVs themselves (Irwin and Michael, 2003). Their framing as a consumer product transcended their association with climate change science amongst our participants. However, subtle variations were apparent in how participants with differing income levels discussed this issue. Extract 4.1 illustrates how such discussions played out in the Penzance focus group; Penzance is a less socio-economically developed urban area.

The day-to-day realities of trying to cover basic living costs render the EV a distant prospect for these participants. These price concerns act as a major deterrent to engaging with EV-related communications. This narrative is produced by a consumerist economic framing of EVs in which knowledges relating to their market value transcends their environmental attributes. Communications regarding EVs therefore become irrelevant if the product is beyond an individual's quotidian purchasing power. While the influence of income inequalities cannot be overlooked here, viewing EVs solely as a consumer product inhibits any opportunity to relate to and develop interest in EVs based on other qualities.

Individuals do engage with and develop dialogues about technologies without considering their status as consumer good (Bell, 2008). However, such dialogues, and so forms of engagement, were absent in this study's focus groups. Such axiomatic insights highlight the need to move away from consumerist narratives to influence more widespread engagement (Grimshaw et al., 2012). When aligned with systems thinking, these discourses reflect that certain societal structures

\section{Extract 4.1: The cost of EVs (1)}

Researcher: "What do you think are the reasons for the lack of information available?

Fred: "One problem is the price, like, you can get a car quickly for a few hundred now. The second hand market isn't there and they are so much more expensive that petrol or diesel...um, I get that they are different and you save petrol but it's crazy, like, have them cheaper and I'm sure we'd know more and see them more" [22, low-med income, secondary]

Aidy: "That's just the companies trying to control the markets mate. The manufacturers will try to get you to pay way over you need to whether it be petrol or electric. It's just the way it is but the crazy difference right now is putting people off." [24, low-med, higher education]

Darren: “True...um, I haven't looked at anything and how can I? I'm on minimum wage and pay for the train every day just to get to work. That costs me over an hour of the work I have to do." [26, low-med income, secondary education]

render moving beyond certain framings of knowledges extremely difficult. Individuals saw the EV as an expensive product and did not refer to its attributes as an innovation associated with climate change. Perhaps this no surprise when the media messaging recalled and discussed by the participants, and academic studies primarily focus on EVs being a consumer product (Axsen and Kurani, 2013; Rezvani et al., 2015). In these circumstances dialogical depth cannot be achieved as individuals simply do not view EVs as a relevant consumer product or anything other than a consumer product. Previous studies focusing on alternative technologies and/or practices have treated this issue as an incapability or deficit of publics due to educational structures that impact science literacy (Kahan et al., 2012). However, as Barr et al. (2011) suggest, individuals are influenced by their position in a neo-liberal society, whereby the objects and subjects individuals interact with are bound to their economic capabilities and societal status (Latour and Weibel, 2005). Hence, it becomes challenging to create communications based on systems thinking, which includes a wide range of actors and alternative framings of knowledges, as individuals self-exclude themselves from dialogues based on their status as a consumer. This was certainly evident amongst our participants.

Moreover, Extract 4.2 from the Mawnan Smith focus group (a more affluent rural community) illustrates how higher income participants engaged in a degree of knowledge-seeking about the $\mathrm{EV}$, before coming to a decision that conventional petrol and diesel vehicles were better suited to their everyday needs. Thus, dialogues were able to develop further relative to Extract 4.1, but again stalled when cost was a direct barrier and the EV's perceived unsuitability to a rural lifestyle provided a barrier to communication.

The Mawnan Smith group's discussion suggests communications relating to a technology are received and interacted with more freely when they are perceived as a viable everyday product. This finding illustrates that communication 


\section{Extract 4.2. The cost of EVs (2)}

Lucy: "Has anyone thought to buy one?" [36, med-high, higher education]

Nigel: "Um, I just don't know enough to even think about it at the moment... all of these have been really interesting". [61, medhigh income, secondary education]

Oscar: "I just wouldn't, um, I know you save petrol costs but the mileage I do is not suitable, and my current turnover of cars is quite high due to my business... I'll just never make up the starting price before I have to get another one and it'll be a vicious circle...um, after I established I wasn't interested in anything else. Maybe they'll get cheaper in a few more years' time." [26, low-med income, higher education]

strategies to publics with these characteristics should focus on the conditions that render EVs more suited to such publics. This resonates with the insights developed by Axsen and Kurani (2013) and builds on Extract 4.1. In summary, participants were able to engage in slightly more critical dialogical interactions with EV-related knowledges. The EVs were not as distantly removed from the economic status of these individuals compared to the participants in Penzance. Hence, the individuals dedicated more time to assessing how relevant EVs were to them. However, the group's level of interaction and engagement with EVs still remained limited. This emphasizes the difficulty of applying systems thinking in scenarios where knowledges are framed narrowly, i.e., by consumerism.

Another commonly discussed (in six of the eight focus groups) aspect of EVs concerned the issue of range and the inconvenience of the time-taken to charge the EV battery. This issue is illustrated in Extract 4.3. Although Truro is Cornwall's administrative and urban center, urban contexts are generally associated with better suitability for EVs (Brady and O'Mahony, 2011; Bakker and Trip, 2013; Krause et al., 2013; Bunce et al., 2014), participants felt their range concerns counterbalanced the potential benefits of EVs. This formed a barrier to engagement and further highlights the importance of overcoming consumer framings of a technology before systems thinking can be applied to understanding richer communication contexts. In this example, price was not the main driver behind participants self-excluding themselves from engaged dialogue, rather it was the suitability of the EV as a relevant product. This yet again demonstrates the influence of neoliberal structures, and so consumerism, on how publics engage with communications about alternative technologies.

In this extract, Todd mentions in passing that he had seen an EV on television a few times "but probably turned over [the TV channel]." This is another example of the technology being situated in a consumerist framing. The opportunity to relate to and engage with the EV based on its other qualities, for example, as an innovation, is again lost. Consequently, the implications for communication and engagement remain dependent on the economic characteristics of the targeted public. Essentially, communications relating to a technology

\section{Extract 4.3. The range of EVs}

Researcher: "Um, yes traveling less was just mentioned, um, how about using electric vehicles?"

Todd: "Ah I have seen them on the telly a few times..., um, not in much detail though. I probably turned over, but they could be a big change in a decade or so." [44, med-high income, secondary education]

Angie: "But some people do have them now. Don't they? It just seems a bit weird charging for so long and having to do that over and over again. The distances just aren't there I don't think." [37, low-med income, higher education]

Todd: "Yeh that is a major issue, um, if you can't go very far what' the point really? But I am sure they will develop...um, there'll probably be a couple more new ways to get about. I've heard hydrogen cars aren't too far away."

Ed: "Yeh, l've heard about the hydrogen ones too, I mean I'd like to know more about electric...um, how far can they go now?" [26, low-med income, secondary education]

Todd: "I think 20-30 miles, or something like that, Is that right?"

Researcher: "I do think they are a little more than that, the pack I'll show you later says around 90 miles."

Todd: "Oh is that so, much better than I remember it being said."

that is not suited to a public as a product should move away from consumerist framings to widen engagement and stimulate interest in a technology's wider attributes (beyond being a consumer product).

Additionally, the mention of EVs in the same light as hydrogen-powered vehicles indicates that EVs are viewed as a technology of the future by these participants. This futureoriented perception of EVs is perhaps not surprising when Cornwall's context is considered. With limited exposure to EVs compared to those in larger urban centers and limited existing EV infrastructure in Cornwall, EVs were not yet widely considered as a current alternative transport option. Indeed, EVs are constructed as a future-product that lacks imminence in solving contemporary issues. They are distant in time and space from individuals' lives. Future framings of this nature have been a common challenge for climate change related science communication. Fundamentally, where communications cannot capture public attention, dialogue is again diminished. A systems thinking approach to understanding communication cannot be developed as the knowledges communicated are limited to a narrow viewpoint, which renders them irrelevant (Felicetti et al., 2015). Thus, the task remains to present communications in a relatable manner to such publics (Moser, 2014; Manzo, 2017). Furthermore, the wider literature in this area suggests that daily experiences play a central role in shaping public perceptions, interpretations and constructs of such technologies 
and knowledges (Barr, 2011; Spence et al., 2012). Linked to this, an interesting reference point that emerged amongst participants in six of the eight focus groups was the electric milk float. Several nostalgic milk float memories were volunteered by participants when asked about their EV familiarity. Milk floats are small EVs, similar to a miniature pick-up truck, which are used to deliver milk from local farms in the United Kingdom. They were commonplace until the mid-1990s but their use and presence on the roads has declined over the past two decades. Perspectives relating to milk floats are illustrated below in an extract from the Roche (a rural area) focus group. Notably, the link to milk floats arose in all four rural groups but just two of the urban groups. The other two urban groups offered no historical links that were relatable to EVs and dialogue was formed around EVs "being a thing for the future". This is again indicative of limited public dialogue in relation to EVs in Cornwall, and the almost instant disengagement initiated by their perceived inadequacy as a commodity compared to petrol and diesel vehicles. Nonetheless, the historical connections to EVs, inspired by familiarity with milk floats, is demonstrated in the Extract 4.4.

Extract 4.4 resonates with philosophical insights concerning the practicalities of forming communications that publics can engage with and construct relevant perspectives from. Latour and Weibel (2005) referred to knowledge becoming familiar through culture. The "milk float" reference illustrates this concept by implying that the tradition of door-to-door milk deliveries is more persistent in the cultural consciousness of rural areas than urban ones. This is indicative of a cultural dimension influencing what EVs "mean" to individuals and essentially what they "are" to an individual (Latour and Weibel, 2005). These individualized constructs can be widespread in a public if a cultural reference is a strong influence on the public (Klein and Kleinmann, 2002; Leonardi, 2011; Ejermo and Hansen, 2015). Milk floats seemed to be as such. Hence, individuals refer to and build

\section{Extract 4.4. "Milk floats"}

Researcher: "Has anyone heard much about electric vehicles?"

Kim: "Well yeah but I'm not very aware of personally." [41, low-med income, secondary education]

Sadie: "Whatever happened to the milk floats...um, they were funny little things. I used to quite like them and the novelty of getting milk from those bottles never wears off." [32, low-med income, secondary education]

Zane: "Yeah I remember the weird hum they had but they were part of the village when I was little, shame they're not about...um, one of those things you lose and don't notice until someone brings it up again." [28, low-med income, higher education education]

Trevor: "And...um, um, they, um, were good around here. Not too much traffic ever, but that's got worse and worse, so they'd probably moan that milkmen are holding up the traffic going into the business park every morning. They were great [laughter]." [46, med-high income, secondary education] additional perspectives around these existing cultural references once they are engaged. Moreover, utilizing such constructs to engage publics revolves around researching the cultural reference points publics may apply to specific technologies (Leonardi, 2011). Although these engrained cultural references can be seen as a source for misconceptions, they do provide an opportunity for a systems thinking approach to engaging publics with EVs. Promoting such extant cultural links provide opportunities to begin dialogical communication that originate from a point of interest relevant to specific publics. Essentially, publics can interact more meaningfully with communications. In so doing, publics can be engaged beyond neoliberal discourses around EVs and systems thinking can be applied in a context where framings of the EV that inspire dialogue go beyond those that simply refer to EVs as a consumer product. Analogies linked to culturally and historically relevant alternative technologies and/or contexts are one way in which communications can express and inspire the development of richer dialogues.

\section{Participant Insights Into Encountered Media Sources}

Discussions regarding participants' preferred and commonly accessed communication sources typically emerged organically within the focus groups. Participants often referred to hearing EV-related communications on the television, the radio, or from friends. Participants also made more general statements along the lines of "I read about this the other day...," without specifying any sources. They seemed to develop their perspectives on communication sources whilst conversing their thoughts with each other. Once more, this highlighted how peripheral EVs were to their daily lives.

When referring to the media it was apparent that different focus group participants applied varying levels of critical thought to what they had encountered in the media. Some reflected on newspaper articles they had read at face value; others expressed more skepticism regarding the motives behind the articles they had come across. They paid particular attention to the perceived credibility of specific media organizations. In this instance the critique applied to media communications seemed to be influenced by education levels, which aligns with some existing studies in this area (Miller et al., 2007; Ryghaug et al., 2011). As illustrated in Extract 4.5 a more critical view was apparent amongst those educated beyond compulsory education. This was a key finding as a critical view of the media occurred in each of the eight focus groups. One of the media articles (see Extract 4.5) that was mentioned is an example of how, as Boykoff and Boykoff (2007) have argued, the media reconstruct knowledges through their political stance. Boykoff and Boykoff (2007) refers to this as a primary journalistic norm. These norms tend to bifurcate responses by either defining how a communication is engaged with (e.g., by influencing individual perspectives and constructs around EVs), or by acting as a barrier to engagement (e.g., if an individual's own views do not align with the political stance of a media outlet). Additionally, unlike much of the other literature in this area (Miller et al., 2007; Prokopy et al., 2015), the income of each participant did not appear to play a role in their engagement 


\section{Extract 4.5. Bringing a critical eye to the media}

Kim: "[referring to a newspaper article they had recently read] um, all the electric makes more emissions." [41, low-med, secondary]

Trevor: "Just shows you can't believe everything, I didn't even think of that if...um, not at all. Shame really." [46, med-high income, secondary education]

Valerie: "That's from the Daily Mail [UK-based national tabloid newspaper] isn't it? I just cannot stand that paper... I mean they are known for, um, I suppose... um, climate skepticism and general environmental disregard, I guess. All the papers have their way of reporting... they are businesses and just want to sell, sell, sell. But some are more reliable than others... glad The Guardian [UK-based national broadsheet newspaper] is in here too [referring to newspapers at the venue] ... that adds a bit of neutrality I guess, um but does it? I just trust it more personally." [32, low-med income, higher education].

Trevor: "True, I don't really trust anyone... but do quickly read things in the paper and some of it sticks and some of it doesn't"

Researcher: Any particular papers?

Trevor: "Nah... just what's there when I'm waiting somewhere or in the garage [place of work]."

with and critical view of specific media sources. There were no clear differences according to age, gender or the urban or rural status of the groups either.

Extract 4.5 touches on the importance of trust in shaping how people engage with different media sources. This relates to a wider body of work emphasizing the importance of trusted media in shaping science communication, for example, in relation to climate change (Schäfer et al., 2018). Thus, by influencing trust levels, the media accessed and encountered by publics plays a key role in facilitating and/or inhibiting a systems thinking approach to communication. A systems thinking approach to communication can only occur when there are well-established networks of trust (making up a system) for knowledges to be mobilized in Best and Holmes (2010). Overall, this indicates that individuals are usually less critical in relation to messages conveyed by their preferred media source (Hargreaves et al., 2003), and that certain newspapers and broadcasters tend to be more trusted by the public than others. The influence of individualized trust was apparent amongst the participants in these focus groups, as illustrated in the extract from the Saltash (an urban location) focus group.

Further, this was a strong theme in this study. Each focus group demonstrated a collective consensus that they would trust $\mathrm{BBC}$ communications relating to EVs. This would perhaps garner a different response if this study took place more recently. The $\mathrm{BBC}$ has faced increased public scrutiny in the UK, particularly around license fee increases and their shift to giving more airtime to right-leaning organizations and institutions regarding social and environmental issues (Lewis and Cushion, 2017). Overall, this study shows how systems thinking around communication cannot be developed if dialogues do not extend beyond a specific
Extract 4.6. Trust in the BBC [UK-based public service broadcaster]

Gordon: "See it[s] not always what you think it is, is it? Burning away coal is what needs to be sorted out first." [44, low-med, secondary]

Victor: “That's just in China isn't it? I should hope they deal with our electricity a bit more cleanly now. They probably use methods over there that we were in the industrial revolution....um, coupled with the fact that that's from The Mail. Good fun that paper, to laugh at... Actually, now l've read that, that reminds me the BBC had something on them a few weeks ago... um, you basically need cleaner energy and they're excellent." [39, med-high, secondary].

framing of a topic. In this case, this was the consumerist framings of products. Further, the limited number of media sources the participants could recall meant that the knowledges publics could base their dialogues on, and indeed construct their own knowledges using, are not easily encountered during their dayto-day lives. Additionally, the dialogues that did develop were still shackled by a neoliberal consumer viewpoint.

\section{CONCLUSIONS}

The findings presented in this paper highlight that EVrelated dialogues are struggling to move beyond neoliberal consumerism. One of the major findings from this study illustrates that EV-related communications are struggling to engage publics in their characteristics associated with mitigating climate change (Nanaki and Koroneos, 2016). Heeding Whitmarsh et al. (2011) and Moser (2016)'s warnings that publics struggle to see how generalized climate change communications can influence their own everyday lives and routines, the development of more reflexive and context-relevant communication approaches has contributed to the production of outputs where these generalized impacts are translated into more familiar contexts, i.e., to local areas and lived experiences (Sheppard, 2015; Moser, 2016; Manzo, 2017). These reflexive and context-relevant communication strategies have provided an exemplar of how publics can be engaged in topics beyond their neoliberal status in society. Unfortunately, the inclusion of EVs in climate change dialogues and their potential role in climate change mitigation was absent in our case.

Ultimately, wider climate change communication research advocates moving away from deficit models, and building on dialogical and reflexive approaches, in order to produce communications that are of relevance to multiple actors and diverse publics (Chilvers, 2013). By including various viewpoints into communications and how they frame certain topics, in a genuinely participatory process, communications can produce more widely relevant and relatable knowledges from the outset (Moser, 2016). This is certainly an area where EV-related communications are lacking. As demonstrated throughout this paper's findings, study participants were unable to recall any uniquely engaging media communications regarding EVs.

Participant dialogues barely develop beyond discussing cost and range. Additionally, none of the participants showed a higher level of engagement with EVs or were they "inspired" 
by a communication they had come across to develop the enthusiasm to pursue the topic of EVs further. We can certainly regard this as a disconnect between publics and the fact that EVs have yet to escape from neoliberal framings which force dialogues to congregate around consumerism. However, the UK's centralized proposal to develop charging infrastructure through an EV Energy Taskforce has the potential to stimulate new dialogues around EVs (Low Carbon Vehicle Partnership, 2020). The influence of this recent activity on whether new dialogues around EVs develop publicly would be interesting to explore. For instance, their potential role in cleaner energy systems (Kester et al., 2018). Moreover, these developments are important in addressing the material realities relevant to EVs, such as transportation, supportive infrastructure and affordability, that can influence familiarity with the technology through increased perceptions around feasibility (Sheppard, 2015). However, such activities may still fall short of engaging publics in the technology as a point of interest beyond their economic viability and uptake as a consumer product. Communications that present EVs as a technological development and novel innovation can widen the opportunities of how publics can engage with them. Waldherr (2011), demonstrates how the media can be influential in engaging publics with innovations. Therefore, new dialogues that focus on the innovative attributes of EVs could be encouraged if such framings of the EV were encountered more easily by publics. This also resonates with the body of academic literature on engaging publics in science and technology by allowing interest in such knowledges to become a culture through publicly shared narratives (Davies et al., 2019).

Systems thinking, which has been deployed in policymaking (Best and Holmes, 2010), offers a more sophisticated approach to understanding communication and has to some extent been adopted by communications concerned with climate change generally. The research of Moser (2016) and van Witsen and Takahashi (2018) indicates that systems thinking could improve current science communication strategies through the intentional collaborative involvement of diverse actors in shaping communications and responding to each other's points of interest. This can address the issues created by narrow and/or limited framings of a technology too. Through systems thinking, the framings of a technology that resonate most with a public, and not necessarily in terms of feasibility and uptake, can be understood to ensure communications can be directed toward relevant audiences. Further, the importance of scale should not be overlooked. Systems thinking recognizes that identifying every nuance within a case is rarely feasible. However, communications can be better planned and implemented if designed as a series of smaller-scale interventions that consider the characteristics of specific publics and remain closely aligned to the context of specific cases (Guenther et al., 2018). The communications should look to maximize opportunities to engage publics beyond consumerist framings if communications are to inspire publics to engage and participate in dialogues regarding EVs (Toscano, 2006). Learning from recent developments in Scandinavian contexts may provide an opportunity here. Though not directly related to communication, Sovacool et al. (2018) and Kester et al. (2018) draw on public perceptions to potentially shape centralized policy, and so national framings, of transport. This provides an interesting context where publics will have a direct link into how EV-related discourses are shaped at a national level. This creates an opportunity for systems thinking to be applied in a case where publics are actively involved in more developed EV-related dialogues. Insights from such a case can potentially provide valuable learning for how publics can be engaged in EVs by more widely accessible sources of knowledges regarding EVs. However, the overarching influence of neoliberalism on consumer preference is a significant challenge for the future of EV-related communication. As highlighted throughout this study, academic research, current public dialogues and the viewpoints publics view communications regarding EVs (including the media sources they encounter) are still heavily aligned with adoption and increased EV consumerism (Egbue and Long, 2012; Rezvani et al., 2015; Liao et al., 2019). In summary, if we refer to the findings of this study, dialogues around EVs can only progress as far as the discussions occurring in Extract 4.2 when neoliberal consumer framings of the technology are dominant. A systems thinking approach to understanding communications that facilitate engaged dialogues with publics would need to draw from a wider range of actors and framings of the EV. Hence, utilizing such reflexive and dialogical methods is important. By understanding unique contextualities, through systems thinking, agendas for public interactions beyond a narrow viewpoint of EVs can be initiated.

Creating new opportunities for communication that are reflexive, relatable and relevant rests upon acknowledging the interlinked uniqueness of geographical, cultural, political and historical contexts of specific publics, and understanding, through systems thinking, how these characteristics can be effectively utilized in efforts to stimulate public dialogues (Toscano, 2006). The systems thinking applied to such contexts will need to include actors that publics trust, including existing print media actors that are relevant, and include perspectives from a wide range of actors (e.g., EV researchers and engineers, transport strategists and members of publics themselves) who can develop dialogues from varied viewpoints. These critically developed dialogues would need to link to relevant and familiar knowledges, such as culturally recognized technologies, to begin new conversations around EVs beyond their status as a consumer good. Further, systems thinking can reveal the synergies between publics and EV-related communications by collaborating with appropriate individuals to develop communications tailored to smaller, but richly understood, cases. This would bring knowledges regarding EVs that are most relevant to a certain context to the forefront. Based on the findings of this study, this would induce higher levels of engagement and opportunities for publics to discuss EVs.

Finally, communications would be enhanced by insights from similar studies being undertaken in different contexts. Particularly in contexts where publics are already more attuned to EV-related knowledges. For example, in Scandinavia (Sovacool, 2017). Future research in such contexts could further provide valuable findings to delineate how systems thinking can be used to explore contexts where publics are themselves key actors in communicating knowledges relating to EVs. Such intuitions, 
gained through systems thinking, would be a valuable resource to communication strategists, including journalists, academics and policy makers, to enhance public engagement, interest and dialogues around EVs.

\section{DATA AVAILABILITY STATEMENT}

The datasets for this article are not publicly available due to the qualitative nature of this research and the detailed case study approach means it would not be possible to adequately anonymise participants in the shared data transcripts. Discussions about accessing the datasets should be directed to the corresponding author.

\section{ETHICS STATEMENT}

The studies involving human participants were reviewed and approved by University of Exeter Medical School Research Ethics

\section{REFERENCES}

Axsen, J., and Kurani, K. S. (2013). Developing sustainability-oriented values: Insights from households in a trial of plug-in hybrid electric vehicles. Glob. Environ. Chang. 23, 70-80. doi: 10.1016/j.gloenvcha.2012.08.002

Bakker, S., and Trip, J. J. (2013). Policy options to support the adoption of electric vehicles in the urban environment. Transp. Res. D Transp. Environ. 25, 18-23. doi: 10.1016/j.trd.2013.07.005

Barr, S. (2011). Climate forums: virtual discourses on climate change and the sustainable lifestyle. Area 43, 14-22. doi: 10.1111/j.1475-4762.2010.00958.x

Barr, S., Gilg, A., and Shaw, G. (2011). 'Helping People Make Better Choices': exploring the behaviour change agenda for environmental sustainability. Appl. Geogr. 31, 712-720. doi: 10.1016/j.apgeog.2010.12.003

Bell, L. (2008). Engaging the public in technology policy. Sci. Commun. 29, 386-398. doi: 10.1177/1075547007311971

Best, A., and Holmes, B. (2010). Systems thinking, knowledge and action: towards better models and methods. Evid. Policy J. Res. Debate Pract. 6, 145-159. doi: 10.1332/174426410X502284

Boykoff, M. T. (2014). Media discourse on the climate slowdown. Nat. Clim. Chang. 4, 156-158. doi: 10.1038/nclimate2156

Boykoff, M. T., and Boykoff, J. M. (2007). Climate change and journalistic norms: a case-study of US mass-media coverage. Geoforum 38, 1190-1204 doi: 10.1016/j.geoforum.2007.01.008

Brady, J., and O'Mahony, M. (2011). Travel to work in Dublin. The potential impacts of electric vehicles on climate change and urban air quality. Transp. Res. D Transp. Environ. 16, 188-193. doi: 10.1016/j.trd.2010.09.006

Bunce, L., Harris, M., and Burgess, M. (2014). Charge up then charge out? drivers' perceptions and experiences of electric vehicles in the UK. Transp. Res. A Policy Pract. 59, 278-287. doi: 10.1016/j.tra.2013.12.001

Burke, M., Ockwell, D., and Whitmarsh, L. (2018). Participatory arts and affective engagement with climate change: the missing link in achieving climate compatible behaviour change? Glob. Environ. Chang. 49, 95-105. doi: 10.1016/j.gloenvcha.2018.02.007

Byass, P. (2011). Systems thinking for health systems strengthening. Public Health 125, 117-118. doi: 10.1016/j.puhe.2010.10.004

Carley, S., Krause, R. M., Lane, B. W., and Graham, J. D. (2013). Intent to purchase a plug-in electric vehicle: A survey of early impressions in large US cites. Transp. Res. D Transp. Environ. 18, 39-45. doi: 10.1016/j.trd.2012.09.007

Carvalho, A. (2007). Ideological cultures and media discourses on scientific knowledge: re-reading news on climate change. Public Understand. Sci. 16, 223-243. doi: 10.1177/0963662506066775
Committee. The patients/participants provided their written informed consent to participate in this study.

\section{AUTHOR CONTRIBUTIONS}

SE conducted the research, data management, and analysis of this study. They also initiated and drafted the article. TT and ML supervised this Ph.D. study. Specifically, TT contributed to drafting the literature review section and provided support during analysis. ML contributed to the analysis methods and contributed to drafting the discussion and conclusions section of this paper. All authors contributed to the article and approved the submitted version.

\section{FUNDING}

This study was part of a Ph.D. funded by the European Social Fund (Grant no. 11200NCO5).

Chan, T., and Goldthorpe, J. (2007). The social stratification of cultural consumption: some policy implications of a research project. Cult. Trends 16, 373-384. doi: 10.1080/09548960701692787

Chilvers, J. (2013). Reflexive engagement?: actors, learning, and reflexivity in public dialogue on science and technology. Sci. Commun. 35, 283-310. doi: $10.1177 / 1075547012454598$

Cornwall Council (2011). Data and Research. Useful Facts and Figures About Cornwall. Cornwall. Cornwall Council. Available online at: http://www. cornwall.gov.uk/default.aspx?page=2035 (accessed January 29, 2017).

Davies, S., Halpern, M., Horst, M., Kirby, D., and Lewenstein, B. (2019). Science stories as culture: experience, identity, narrative and emotion in public communication of science. J. Sci. Commun. 18:A01. doi: 10.22323/2.18050201

DCLG (2010). English Indices of Deprivation 2010. Department for Communities and Local Government. Available online at: https://data.gov.uk/dataset/ 4c4c4e50-0925-4ae6-b45c-ca8a350bd5c6/english-indices- of-deprivation2010 (accessed June 11, 2020).

de Rubens, G. Z., Noel, L., and Sovacool, B. (2018). Dismissive and deceptive car dealerships create barriers to electric vehicle adoption at the point of sale. Nat. Energy 3, 501-507. doi: 10.1038/s41560-018-0152-x

Egbue, O., and Long, S. (2012). Barriers to widespread adoption of electric vehicles: an analysis of consumer attitudes and perceptions. Energy Policy 48, 717-729 doi: 10.1016/j.enpol.2012.06.009

Ejermo, O., and Hansen, H. (2015). How important are local inventive milieus: the role of birthplace, high school and University education. Geoforum 65, 387-397. doi: 10.1016/j.geoforum.2014.12.002

Elo, S., and Kyngäs, H. (2007). The qualitative content analysis process. Res. Methodol. 62, 107-115 doi: 10.1111/j.1365-2648.2007.04569.x

Feldman, L., Hart, P., Leiserowitz, A., Maibach, E., and Roser-Renouf, C. (2015). Do hostile media perceptions lead to action? The role of hostile media perceptions, political efficacy, and ideology in predicting climate change activism. Commun. Res. 44, 1099-1124. doi: 10.1177/0093650214565914

Felicetti, A., Niemeyer, S., and Curato, N. (2015). Improving deliberative participation: connecting mini-publics to deliberative systems. Eur. Politic. Sci. Rev. 8, 427-448. doi: 10.1017/S1755773915000119

Foulger, T. (2009). External conversations: an unexpected discovery about the critical friend in action research inquiries. Action Res. 8, 135-152. doi: 10.1177/1476750309351354

Graham-Rowe, E., Gardner, B., Abraham, C., Skippon, S., Dittmar, H., Hutchins, R., et al. (2012). Mainstream consumers driving plug-in battery-electric and plug-in hybrid electric cars: a qualitative analysis of responses and evaluations. Transp. Res. A Policy Pract. 46, 140-153. doi: 10.1016/j.tra.2011.09.008 
Grimshaw, J., Eccles, M., Lavis, J., Hill, S., and Squires, J. (2012). Knowledge translation of research findings. Implement. Sci. 7:50. doi: 10.1186/1748-5908-7-50

Grundmann, R., and Scott, M. (2012). Disputed climate science in the media: do countries matter? Public Understand. Sci. 23, 220-235. doi: $10.1177 / 0963662512467732$

Guenther, L., Weingart, P., and Meyer, C. (2018). "Science is Everywhere, but No One Knows It": assessing the cultural distance to science of rural South African publics. Environ. Commun. 12:1-6. doi: 10.1080/17524032.2018.1455724

Hajer, M., and Stengers, B. (2012). Who speaks for the climate: making sense of media reporting on climate change. Camb. Rev. Int. Aff. 25, 298-300. doi: 10.1080/09557571.2012.679809

Hargreaves, I., Lewis, J., and Speers, T. (2003). Towards a Better Map: Science, the Public and Media. Report for the Economic and Social Research Council. Available online at: http://www.cardiff.ac.uk/jomec/resources/Mapdocfinal_ tcm6-5505.pdf (accessed June 11, 2020).

Hernández, A., Ruano, A., Marchal, B., San Sebastián, M., and Flores, W. (2017). Engaging with complexity to improve the health of indigenous people: a call for the use of systems thinking to tackle health inequity. Int. J. Equity Health 16:26. doi: 10.1186/s12939-017-0521-2

Hoggart,K., Lees, L., and Davies, A. (2002). Researching Human Geography. London: Routledge Publishing.

Irwin, A., and Michael, M. (2003). Science, Social Theory and Public Understanding. Berkshire: Open University Press.

Jackson, M. C. (2000). Systems Approaches to Management. New York, NY: Kluwer Academic/Plenum.

Jerit, J., Barabas, J., and Bolsen, T. (2006). Citizens, knowledge, and the information environment. Am. J. Polit. Sci. 50, 266-282. doi: 10.1111/j.1540-5907.2006.00183.x

Kahan, D., Peters, E., Wittlin, M., Slovic, P., Ouellette, L., Braman, D. and Mandel, G. (2012). The polarizing impact of science literacy and numeracy on perceived climate change risks. Nat. Clim. Change 2, 732-735. doi: 10.1038/nclimate1547

Kalim, K., Carson, E., and Cramp, D. (2006). An illustration of whole systems thinking. Health Serv. Manag. Res. 19, 174-185. doi: 10.1258/095148406777888116

Kester, J., Noel, L., de Rubens, G. Z., and Sovacool, B. (2018). Policy mechanisms to accelerate electric vehicle adoption: a qualitative review from the Nordic region. Renew. Sust. Energy Rev. 94, 719-731. doi: 10.1016/j.rser.2018.05.067

Klein, H. K., and Kleinmann, D. L. (2002). The social construction of technology: structural considerations. Sci. Technol. Hum. Values 27, 28-52. doi: 10.1177/016224390202700102

Krause, R. M., Carley, S. R., Lane, B. W., and Graham, J. D. (2013). Perception and reality: public knowledge of plug-in electric vehicles in 21 U.S. cities. Energy Policy 63, 433-440. doi: 10.1016/j.enpol.201 3.09.018

Krueger, R. A. (2002). Designing and Conducting Focus Group Interviews. Minneapolis, MN: University of Minessota. Available online at: http://www.comm.umn.edu/ akoerner/courses/5431-S10/KruegerFocusGroupInterviews.pdf (accessed June 10, 2020).

Langheim, R., Skubel, M., Chen, X., Maxwell, W., Peterson, T., Wilson, E., et al. (2014). Smart grid coverage in U.S. newspapers: characterizing public conversations. Electr. J. 27, 77-87. doi: 10.1016/j.tej.2014.05.008

Latour, B., and Weibel, P. (2005). Making Things Public: Atmospheres of Democracy. Cambridge, MS: MIT Press.

Lave, R. (2012). Neoliberalism and the production of environmental knowledge. Environ. Soc. 3, 19-38. doi: 10.3167/ares.2012.030103

Lebeau, K., Mierlo, J., Lebeau, P., Mairesse, O., and Macharis, C. (2013). Consumer attitudes towards battery electric vehicles: a large-scale survey. Int. J. Electr. Hybrid Vehicles 5:28. doi: 10.1504/IJEHV.2013.053466

Leischow, S., Best, A., Trochim, W., Clark, P., Gallagher, R., Marcus, S., et al. (2008). Systems thinking to improve the public's health. Am. J. Prev. Med. 35, S196-S203. doi: 10.1016/j.amepre.2008.05.014

Leonardi, P. M. (2011). Innovation blindness: culture, frames, and cross-boundary problem construction in the development of new technology concepts. Organ. Sci. 22, 347-369 doi: 10.1287/orsc.1100.0529

Lewis, J., and Cushion, S. (2017). Think tanks, television news and impartiality. J. Stud. 20, 480-499. doi: 10.1080/1461670X.2017.13 89295
Liao, F., Molin, E., Timmermans, H., and van Wee, B. (2019). Consumer preferences for business models in electric vehicle adoption. Transp. Policy 73, 12-24. doi: 10.1016/j.tranpol.2018.10.006

Lott, J. R., and Hasset, K. A. (2014). Is newspaper coverage of economic events politically biased? Public Choice 160, 65-108. doi: 10.1007/s11127-014-0171-5

Low Carbon Vehicle Partnership (2020). EV Energy Taskforce. Avaliable online at: https://www.lowcvp.org.uk/projects/electric-vehicle-energy-taskforce.htm. (accessed March 03, 2020).

Mahony, M. (2014). Climate change and the geographies of objectivity: the case of the IPCC's burning embers diagram. Trans. Instit. Br. Geogr. 40, 153-167. doi: $10.1111 / \operatorname{tran} .12064$

Manzo, K. (2017). The usefulness of climate change films. Geoforum 84, 88-94. doi: 10.1016/j.geoforum.2017.06.006

Martens, T., Garrelts, H., Grunenberg, H., and Lange, H. (2009). Taking the heterogeneity of citizens into account: flood risk communication in coastal cities - a case study of Bremen. Nat. Hazards Earth Syst. Sci. 9, 1931-1940. doi: 10.5194/nhess-9-1931-2009

McClanahan, T. R., Cinner, J., and Graham, N. (2009). Identifying reefs of hope and hopeful actions: contextualizing environmental, ecological, and social parameters to respond effectively to climate change. Conserv. Biol. 23, 662-671. doi: 10.1111/j.1523-1739.2008.01154.x

Miller, E., Bell, L., and Buys, L. (2007). Public understanding of carbon sequestration in Australia: socio-demographic predictors of knowledge, engagement and trust. Austr. J. Emerg. Technol. Soc. 5, 15-33. Available online at: https://eprints.qut.edu.au/12353/

Moser, S. C. (2014). Communicating adaptation to climate change: the art and science of public engagement when climate change comes home. Wiley Interdiscip. Rev. Clim. Change 5, 337-358. doi: 10.1002/wcc. 276

Moser, S. C. (2016). Reflections on climate change communication research and practice in the second decade of the 21st century: what more is there to say? Wiley Interdiscip. Rev. Clim. Change 7, 345-369. doi: 10.1002/wcc.403

Nanaki, E., and Koroneos, C. (2016). Climate change mitigation and deployment of electric vehicles in urban areas. Renew. Energy 99, 1153-1160 doi: 10.1016/j.renene.2016.08.006

Nicholson-Cole, S. A. (2005). Representing climate change futures: a critique on the use of images for visual communication. Comput. Environ. Urban Syst. 29, 255-273. doi: 10.1016/j.compenvurbsys.2004.05.002

Nowotny, H. (2014). Engaging with the political imaginaries of science: near misses and future targets. Public Understand. Sci. 23. 16-20. doi: $10.1177 / 0963662513476220$

Olausson, U. (2009). Global warming - global responsibility? Media frames of collective action and scientific certainty. Public Understand. Sci. 18, 421-436. doi: 10.1177/0963662507081242

O'Neill, S. (2019). More than meets the eye: a longitudinal analysis of climate change imagery in the print media. Climatic Change doi: 10.1007/s10584-019-02504-8. [Epub ahead of print].

ONS (2011). The 2011 Rural/Urban Classification. Office of National Statistics. Available online at: http://www.ons.gov.uk/ons/guide-method/geography/ products/area-classifications/2011-rural-urban/index.html (accessed April 20, 2017).

Painter, J., and Ashe, T. (2012). Cross-national comparison of the presence of climate scepticism in the print media in six countries, 2007-2010. Environ. Res. Lett. 7, 1-8. doi: 10.1088/1748-9326/7/4/044005

Painter, J., and Gavin, N. (2015). Climate skepticism in british newspapers, 2007-2011. Environ. Commun. 10, 432-452. doi: 10.1080/17524032.2014.995193

Patton, M. (1990). "Purposive sampling," in Qualitative Evaluation and Research Methods, ed. M. Patton (Beverley Hill, CA: SAGE publications), 169-186.

Peters, A., and Dutschke, E. (2014). How do consumers perceive electric vehicles? A comparison of german consumer groups. J. Environ.Policy Plann. 16, 358-377. doi: 10.1080/1523908X.2013.879037

Plotz, P., Schneider, U., Globisch, J., and Dütschke, E. (2014). Who will buy electric vehicles? Identifying early adopters in Germany. Transp. Res. A Policy Pract. 67, 96-109 doi: 10.1016/j.tra.2014.06.006

Prokopy, L., Arbuckle, J., Barnes, A., Haden, V., Hogan, A., Niles, M., et al. (2015). Farmers and climate change: a cross-national comparison of beliefs and risk perceptions in high-income countries. Environ. Manage. 56, 492-504. doi: 10.1007/s00267-015-0504-2 
Rawlins, B. L., and Bowen, S. A. (2005). "Publics," in Encyclopedia of Public Relations, 2 ed R. L. Heath (California, CA: SAGE Publications), 718-721.

Rezvani, Z., Jansson, J., and Bodin, J. (2015). Advances in consumer electric vehicle adoption research: a review and research agenda. Transp. Res. D Transp. Environ. 34, 122-136. doi: 10.1016/j.trd.2014.10.010

Rudman, D. L. (2006). Shaping the active, autonomous and responsible modern retiree: an analysis of discursive technologies and their links with neo-liberal political rationality. Ageing Soc. 26, 181-201. doi: 10.1017/S0144686X05004253

Ryghaug, M., Sorensen, K. H., and Naess, R. (2011). Making sense of global warming: Norwegians appropriating knowledge of anthropogenic climate change. Public Understand. Sci. 20, 778-795 doi: 10.1177/0963662510362657

Schäfer, M., Füchslin, T., Metag, J., Kristiansen, S., and Rauchfleisch, A. (2018). The different audiences of science communication: a segmentation analysis of the Swiss population's perceptions of science and their information and media use patterns. Public Understand. Sci. 27, 836-856 doi: 10.1177/0963662517752886

Schmidt, A., Ivanova, A., and Schafer, M. S. (2013). Media attention for climate change around the world: a comparative analysis of newspaper coverage in 27 countries. Glob. Environ. Change 23, 1233-1248 doi: 10.1016/j.gloenvcha.2013.07.020

Schreier, M. (2012). Qualitative Content Analysis in Practice. London: SAGE Publications.

Schweizer, S., Davis, S., and Thompson, J. (2013). Changing the conversation about climate change: a theoretical framework for place-based climate change engagement. Environ Commun. 7, 42-62. doi: 10.1080/17524032.2012.753634

Sheppard, S. R. J. (2015). Making climate change visible: a critical role for landscape professionals. Landsc. Urban Plan. 142, 95-105. doi: 10.1016/j.landurbplan.2015.07.006

Sovacool, B. (2017). Experts, theories, and electric mobility transitions: toward an integrated conceptual framework for the adoption of electric vehicles. Energy Res. Soc. Sci. 27, 78-95. doi: 10.1016/j.erss.2017.02.014

Sovacool, B., Noel, L., Kester, J., and de Rubens, G. Z. (2018). Reviewing Nordic transport challenges and climate policy priorities: Expert perceptions of decarbonisation in Denmark, Finland, Iceland, Norway, Sweden. Energy 165, 532-542. doi: 10.1016/j.energy.2018.09.110

Spence, A., Poortinga, W., Butler, C., and Pidgeon, N. (2011). Perceptions of climate change and willingness to save energy related to flood experience. Nat. Clim. Chang 1, 46-49. doi: 10.1038/nclimate1059

Spence, A., Poortinga, W., and Pidgeon, N. (2012). The psychological distance of climate change. Risk Anal. 32, 957-972. doi: 10.1111/j.1539-6924.2011.01695.x

Tiessen, H., Brklacich, M., Breulmann, G., and Menezes, R. S. C. (2008). Communicating Global Change Science to Society. SCOPE Project. (Washington: Island Press.

Toscano, P. (2006). The study of global solutions: a postmodern systems thinking view of grounded theory/grounded action. World Fut. 62, 505-515. doi: $10.1080 / 02604020600912848$
Trench, B., and Miller, S. (2012). Policies and practices in supporting scientists' public communication through training. Sci. Public Policy 39, 722-731. doi: $10.1093 / \mathrm{scipol} / \mathrm{scs} 090$

UK Government (2012). Reducing Greenhouse Gases and Other Emissions From Transport. London: UK Government Policy. Available online at: https:// www.gov.uk/government/policies/reducing-greenhouse-gases-and-otheremissions-from-transport/supporting-pages/ultra-low-emission-vehicles (accessed March 10, 2017).

van Witsen, A., and Takahashi, B. (2018). Knowledge-based journalism in science and environmental reporting: opportunities and obstacles. Environ. Commun 12, 717-730. doi: 10.1080/17524032.2018.1455723

Verger, A., Edwards, D., and Altinyelken, H. (2014). Learning from all? The world bank, aid agencies and the construction of hegemony in education for development. Comp. Educ. 50, 381-399. doi: 10.1080/03050068.2014.9 18713

Waldherr, A. (2011). "The mass media as actors in innovation systems," in Innovation Policy and Governance in High-Tech Industries, 1st Edn, eds. J. Bauer, A. Lang, and V. Schneider (New York, NY: Springer Link), 77-100.

Wals, A., Lans, T., and Kupper, H. (2011). Blurring the boundaries between vocational education, business and research in the agri-food domain. J. Vocat. Educ. Train. 64, 3-23. doi: 10.1080/13636820.2011.586129

Welsh, I., and Wynne, B. (2013). Science, scientism and imaginaries of publics in the UK: passive objects, incipient threats. Sci. Culture 22, 540-566 doi: 10.1080/14636778.2013.764072

Whitmarsh, L., O'Neill, S., and Lorenzoni, I. (2011). Climate change or social change? Debate within, amongst, and beyond disciplines. Environ. Plann. A 43, 258-261. doi: 10.1068/a43359

Wolf, J., and Moser, S. C. (2011). Individual understandings, perceptions, and engagement with climate change: insights from in-depth studies across the world. Wiley Interdiscip. Rev. Clim. Change 2, 547-569. doi: 10.1002/wcc.120

Wynne, B. E. (1992). Misunderstood misunderstanding: social identities and public uptake of science. Public Understand. Sci. 1, 281-304. doi: $10.1088 / 0963-6625 / 1 / 3 / 004$

Conflict of Interest: The authors declare that the research was conducted in the absence of any commercial or financial relationships that could be construed as a potential conflict of interest.

Copyright (ㅇ) 2020 Esmene, Taylor and Leyshon. This is an open-access article distributed under the terms of the Creative Commons Attribution License (CC BY). The use, distribution or reproduction in other forums is permitted, provided the original author(s) and the copyright owner(s) are credited and that the original publication in this journal is cited, in accordance with accepted academic practice. No use, distribution or reproduction is permitted which does not comply with these terms. 